\title{
Long-term improvement of breast cancer survivors' quality of life by a 2-week group physical and educational intervention: 5-year update of the 'PACThe' trial
}

Fabrice Kwiatkowski ${ }^{1}$, Marie-Ange Mouret-Reynier ${ }^{2}$, Martine Duclos ${ }^{3}$, François Bridon ${ }^{4}$, Thierry Hanh ${ }^{5}$, Isabelle Van Praagh-Doreau ${ }^{2}$, Armelle Travade ${ }^{6}$, Marie-Paule Vasson ${ }^{7}$, Sylvie Jouvency ${ }^{7}$, Christian Roques ${ }^{8}$ and Yves-Jean Bignon*,9

${ }^{1}$ Department of Clinical Research, Comprehensive Anticancer Centre Jean Perrin, 58, rue Montalembert, 63011 Clermont-Ferrand, France; ${ }^{2}$ Department of Oncology, Comprehensive Anticancer Centre Jean Perrin, 58, rue Montalembert, 63011 ClermontFerrand, France; ${ }^{3}$ Department of Sport Medicine and Functional Explorations, Gabriel Montpied University Hospital, Place Henri Dunant, 63000 Clermont-Ferrand, France; ${ }^{4}$ Institut de Formation des Masseurs-Kinésithérapeutes, Centre Hospitalier Lacarin, 3 Boulevard Denière, 03200 Vichy, France; ${ }^{5}$ Centre Nutritionnel de Vichy, 111 Boulevard des États Unis, 03200 Vichy, France; ${ }^{6}$ Department of Senology, Centre République, 99 avenue de la République, 63000 Clermont-Ferrand, France; ${ }^{7}$ Department of Nutrition, Comprehensive Anticancer Centre Jean Perrin, 58, rue Montalembert, 63011 Clermont-Ferrand, France; ${ }^{8}$ University of Toulouse, Physical and Rehabilitation Medicine, 31059 Toulouse, France and ${ }^{9}$ Department of Oncogenetics, Comprehensive Anticancer Centre Jean Perrin, 58, rue Montalembert, 63011 Clermont-Ferrand, France

Background: The advantages of adapted physical activity and nutritional education (APANE) on breast cancer prognosis and quality of life $(\mathrm{Q} \circ \mathrm{L})$ are well known, but long-term results are lacking.

Methods: A randomised controlled trial testing a 2-week intervention in hydrothermal centres including APANE enrolled 251 patients post-chemotherapy. QoL and weight control were significantly improved at 12 months. A 5 -year follow-up was performed to evaluate the persistence of improvements.

Results: QoL increase (SF36) was persistent: effect-size at $2,3,4$ and 5 years equalled respectively $0.27(-0.01 ; 0.56), 0.28(-0.02 ; 0.58)$, $0.41(0.02 ; 0.81)$ and $0.45(0.11 ; 0.80)$. Weight control observed after intervention lasted 2 years: $2.7 \%$ decrease at 1 year $(P=0.0085), 2.5 \%$ at 2 years $(P=0.025)$; and respectively for waist $-2.4 \%(-3.6 ;-1.1)(P=0.000014)$ and $-1.3 \%(-2.5 ;-0.1)(P=0.0072)$.

Conclusions: A 2-week intervention in hydrothermal centres performed shortly after chemotherapy can durably improve breast cancer patients' QoL and reduce weight.

\section{RATIONALE}

Long term results of randomised controlled trials (RCT) testing dietary and/or physical interventions in cancer patients are scarce.
In most studies, the objective is behavioural change between inclusion and the end of the training period (that is, from a few weeks to several months) and long-term evaluations usually do not exceed 1 year post-intervention (Zhu et al, 2016). Also, patients'

*Correspondence: Professor Y-J Bignon; E-mail: Yves-Jean.Bignon@Clermont.Unicancer.fr

Received 2 November 2016; revised 28 March 2017; accepted 30 March 2017; published online 20 April 2017

(C) 2017 Cancer Research UK. All rights reserved 0007-0920/17 
adherence to recommendations often decline significantly after the supervised intervention is completed (Courneya et al, 2007, 2009; Trinh et al, 2014; Greenlee et al, 2016). The PACThe trial is a 2week physical/nutritional intervention in hydrothermal centre (SPA Sana-Per-Aquam), whose main objective was an increase of health-related quality of life (QoL) 1 year post-intervention, with follow-up over 5 years. PACThe protocol and primary outcomes have been described in previous articles (Kwiatkowski et al, 2013; Mourgues et al, 2014). Long-term results are now available.

\section{PATIENTS AND METHODS}

PACThe was a prospective multicenter RCT testing the impact on QoL of a single 2-week group intervention (7-12 patients at a time). Other endpoints included sleep, anxiety/depression, weight control and some biological parameters. Intervention included daily group supervised physical training, dietary education, physiotherapy and psychological support. Three hydrothermal cities from central France participated in the trial: Vichy, Le-MontDore and Châtel-Guyon. Selection criteria were non-metastatic breast cancer patients with invasive tumours, aged from 18 to 75 years, in complete remission after treatment of their disease (including chemotherapy).

Anthropometric measures were performed by nutritionists (weight, waist circumference and body composition by impedanceometry) at inclusion and $6,12,18,24$ and 36 months postinclusion. Patients answered questionnaires at the same periods, plus at year 4 and 5 after inclusion: SF36 for QoL (Ware and Sherbourne, 1992; Ware et al, 1994; Richard et al, 2000), HAD hospital anxiety and depression (Zigmond and Snaith, 1983; Lépine et al, 1985) and Ricci and Gagnon questionnaire for physical/sedentary activities (Walger, 2009).

Patient consent was obtained before the study. The trial was performed in compliance with the Helsinki declaration and approved by AFSSAPS (French Agency for Sanitary Security of Health Products), the French National Committee controlling personal computerised data (CNIL), and the regional Ethics Committee (CPP Sud-Est-6 in March 2008). It was registered in ClinicalTrials.gov (NCT01563588).

Statistics. Impact of the intervention at different time points is described with effect-sizes $(\mathrm{ES}=$ difference between mean values by allocation group divided by the common standard deviation) and their 95\% confidence intervals (95\% CI). QoL scores are standardised with a $0-100$ scale. All tests are two-sided and $P$-values $\leqslant 0.05$ are considered significant. SEM software (Kwiatkowski et al, 2000) was used to perform the statistics.

\section{RESULTS}

Flowchart of accrual and response rates per period. The response rate at 5 years was $65 \%$ in the SPA group and $58 \%$ in the control group (60\% overall). Anthropometric data were obtained at 2 years in 82 and $82 \%$ of participants, respectively, and at 3 years in 43 and $46 \%$ of participants (Figure 1). Patient characteristics, reported in our 2013 article, are not duplicated here. Median follow-up of participants was 65 months (13-96).

Evolution of patients' quality of life over 5 years. Overall patients' QoL (all dimensions together) was significantly improved by the SPA intervention (Figure 2A), the widest difference between curves occurring just after the intervention (measured at 6 months):

The effect-size of the intervention on QoL over the whole follow-up period was $0.33(0.23 ; 0.43)$. Effect-sizes at various time points were: 6 months $=0.63 \quad(0.37 ; 0.89), \quad P=0.000003 ; 1$ year $=0.29(0.03 ; 0.55), P=0.032 ; 18$ months $=0.29(0.02 ; 0.56)$, $P=0.037 ; 2$ years $=0.27(-0.01 ; 0.56), P=0.06 ; 3$ years $=0.28$ $(-0.02 ; 0.58), P=0.064 ; 4$ years $=0.41(0.02 ; 0.81), P=0.039$ and 5 years $=0.45(0.11 ; 0.80), P=0.0093$.

To limit possible attrition bias and curtail the person-effect, this comparison was made using the QoL variation from baseline (inclusion) in percents. Similar shapes of curves per group were obtained. The overall effect-size was however smaller: 0.19 (0.08; 0.30) $(P=0.0009)$

Considering the two main dimensions of the SF36 questionnaire (Ware et al, 1994), the impact of the intervention was significant $\left(P<10^{-7}\right)$ for both the mental and the physical sub-scores (difference between curves; Figure 2B). The correlation between both scores was stronger among participants from the SPA group $(r=0.85)$ than among the control group $(r=0.80, r$-difference $P=0.0012)$. SF36 physical and mental scores were highly correlated to the level of physical activity (resp. $r=0.29$ and $\left.r=0.27, P<10^{-7}\right)$.

Anxiety and depression evolution over 5 years. Intervention had a limited impact on anxiety, except at 6 months $(P=0.025)$. Depressive symptoms were more influenced by the intervention at 6 months $P=0.000014$, effect-size $=-0.46(-0.73 ;-0.19)$ and at 1 year $-0.34(-0.61 ;-0.08)$. However, gains after 1 year were not significant $(-0.28 \leqslant$ effect-size $\leqslant-0.12$ till 5 years $)$.

Anthropometric measures and activity/sedentarity. Over the 3-year follow-up, 20\% participants from both groups had weight increase of $>5 \%$. On average, weight variation from baseline was $-1.1 \%$ in the SPA group $(95 \% \mathrm{CI}=(-1.7 ;-0.6))$ vs $0.7 \%(0.2$; $1.2)$ in the control group $(P=0.0000016)$. Figure 3 exhibits variations of the weight and abdominal circumference from baseline at each time: for the weight, the overall effect-size was $-0.42(-0.55 ;-0.29)\left(\mathrm{p} \approx 10^{-5}\right)$. This was similar if patients were stratified according to BMI at inclusion: for $\mathrm{BMI}<25 \mathrm{~kg} \mathrm{~m}^{-2}$, the probability associated to the difference was 0.00045 for $\mathrm{BMI}>25 \mathrm{~kg} \mathrm{~m}^{-2}, P=0.0021$. Overall, the impact of the intervention on weight control did not last more than 2 years.

The impact of the intervention on the reduction of abdominal adiposity (measured using waist-girth variation from baseline) was stronger: on average over 3 years, $-2.0 \%(-2.5 ;-1.4)$ in the SPA group vs $0.7 \%(-0.1 ; 1.5)$ in the control group $\left(P<10^{-7}\right)$.

Overall, weight variations significantly correlated with the level of physical activity $(P=0.000002)$, which influenced weight variation by $\approx 5 \%(r=-0.17)$. The SPA intervention interacted with this correlation $(P=0.002)$ : correlation between activity and weight decrease was significant in the SPA group $(r=-0.24$, $P=0.000001)$ but not in the control group $(r=-0.05, P=0.29)$. The multivariate analysis of parameters influencing abdominal circumference over time selected only three significant items: allocation group $\left(P=2.6 \times 10^{-7}\right)$, caloric input $(P=0.0000043)$ and physical activity $(P=0.0026)$. In particular, menopausal status and time after intervention were not significant.

\section{DISCUSSION}

Because of its simple design (a 2-week multidisciplinary intervention in SPA) and the promising middle term results (Kwiatkowski et al, 2013), PACThe trial appeared to be an efficient strategy to help breast cancer survivors improve their QoL. The effect-size of the intervention on QoL was moderate at 6 months and small at 1 year. PACThe performed better at 6 months than standard protocols: in a large meta-analysis (Duijts et al, 2011), effect-size of physical activity on QoL was $0.30(0.12 ; 0.48)$. Adherence and gains usually fade with time (Courneya et al, 2007, 2009; Greenlee et al, 2016). This 5-year update shows that improvements obtained 


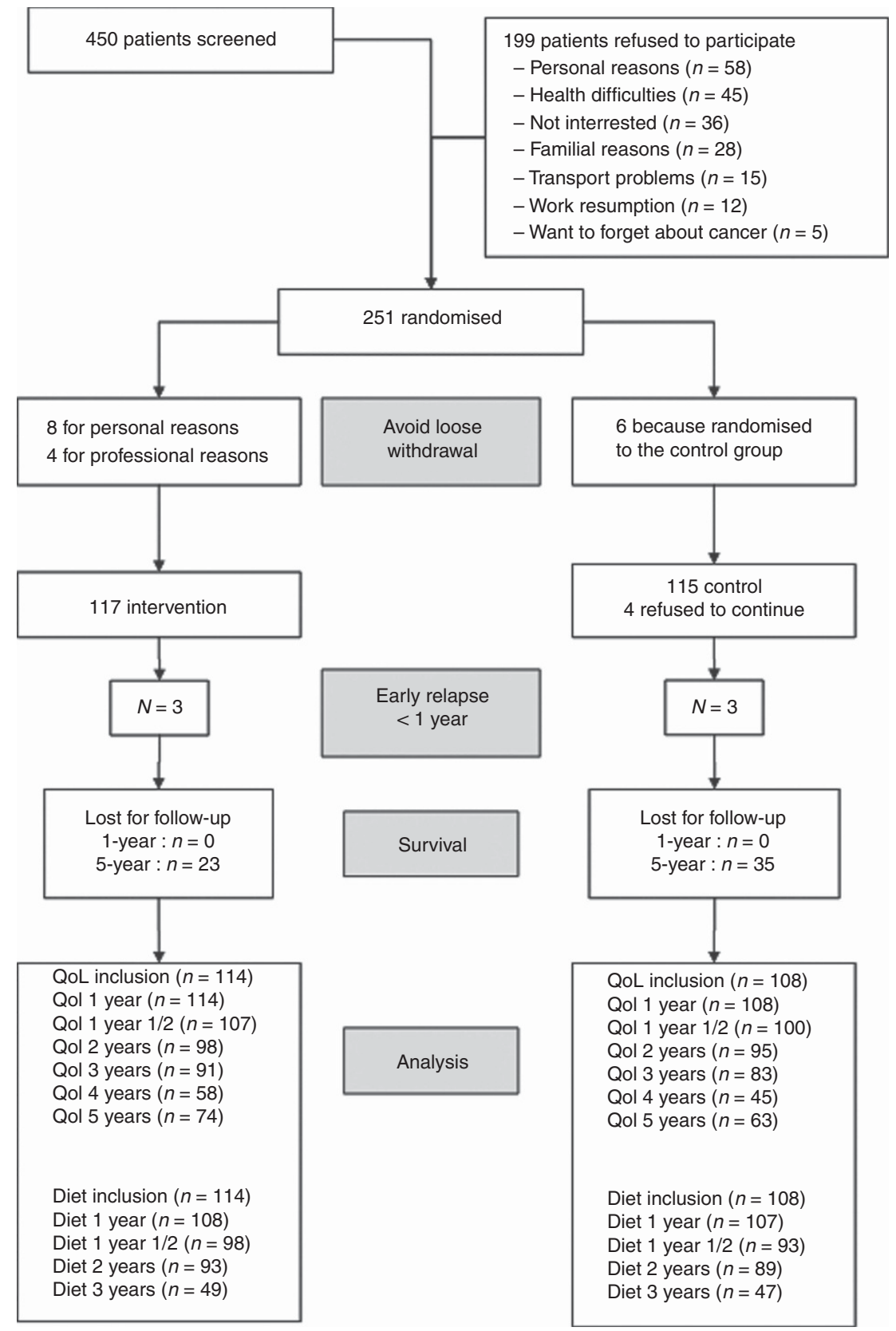

Figure 1. Inclusion flowchart and data count at each time-point. Qol, quality of life; diet, nutritional + anthropometric data.

post-intervention are remarkably durable. PACThe intervention seems to provide a benefit that propels patients to another QoL level, unattainable under usual circumstances.

However, the 60\% 5-year response rate in our study limits the reliability of our estimates and the strength of our conclusion: an attrition bias cannot be excluded even though analysis of individual variations from baseline remained significant $(P=0.0009)$.

Depressive symptoms are one of the most frequent side-effects of cancer, even after complete remission (Massie, 2004; Reich et al, 2008). The gains provided by the intervention at 6 months and at 1 year were higher than those reported in two meta-analyses (Duijts et al, 2011; Craft et al, 2012). This advantage lasted till 5 years, but not significantly.

Weight control in our study did not exceed 2 years, after significant differences at 6 months and 1 year. Interestingly, the intervention was more efficient on abdominal adiposity than on weight, with more lasting and significant differences in abdominal circumference reduction. Considering the particular negative impact of central adiposity on breast cancer prognosis (Ibrahim and Al-Homaidh, 2011; Sun et al, 2015), our intervention appears to be a good strategy to limit this risk. The risk reduction of premature mortality and cardio-metabolic diseases is also concerned (Nichols et al, 2009; Després, 2012). The PACThe intervention ameliorated participants' perceived self-efficacy and their positive behavioural beliefs on the adherence to long-term behavioural changes (Aparicio-Ting et al, 2015).

\section{CONCLUSION}

Overall, our intervention demonstrated many advantages: PACThe only necessitated a 2-week participation for patients. This combination of physiotherapy, physical exercises, nutrition and group support appeared to induce a real motivation shift in patients which permitted a durable amelioration of QoL that correlated with more rapid resumption of professional and 

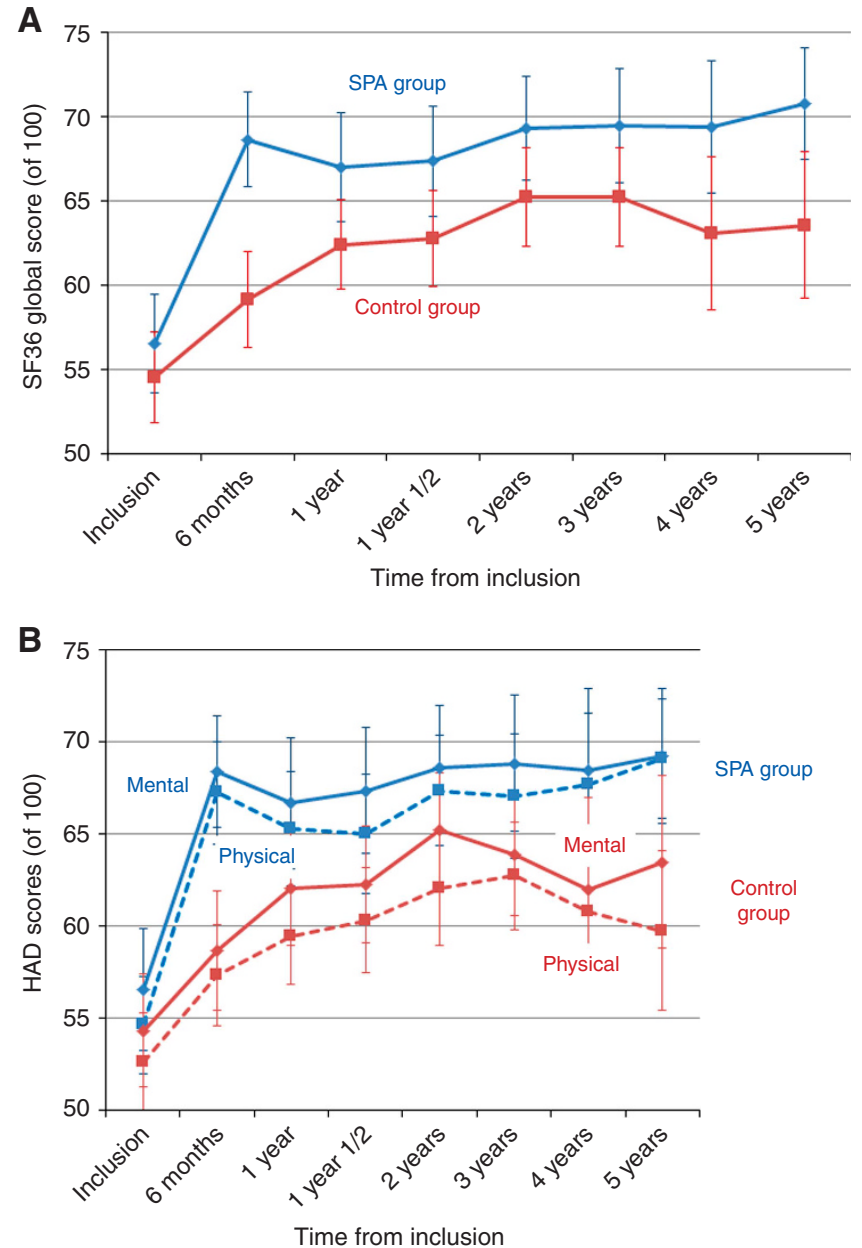

Figure 2. Evolution of SF36 quality of life scores (ranking from $0=$ worst to 100 = best) according to allocation group (A) QoL global score (B) Mental and Physical sub-scores (error bars correspond to $95 \%$ confidence interval).

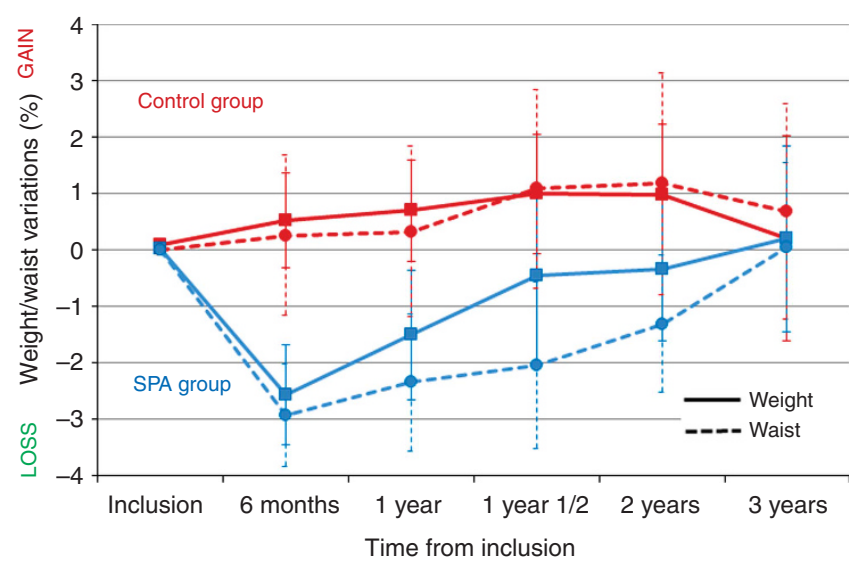

Figure 3 . Weight and waist-girth variations by allocation group over 3 years $(=\%$ differences between measures at inclusion and those at each time points) Error bars correspond to $95 \%$ confidence interval).

occupational activities. Moreover, SPA costs were totally compensated by the reduction of professional absenteeism and medical fees following chemotherapy (Mourgues et al, 2014). Such a strategy should be investigated to other cancer locations where remission rates are high and QoL a priority target.

\section{ACKNOWLEDGEMENTS}

All patients participating in the trial, actors of the programme at the Centre Jean Perrin, Pôle Santé République (Clermont-Ferrand), Thermal resorts (Vichy, Le-Mont-Dore, Châtel-Guyon) and other supports are as follows in alphabetic order: Achard JL, Antolin O, Aubel C, Auclair C, Audibert M, Bagard C, Banh VS, Bargain C, Bargeas S, Béraud JF,Bezy O, Birot G, Bouchet F, Boulonne P, Bourlois G, Boussion V, Breton-Gilet A, Broult-De Macedo M, Brut E, Camus A, Chalabi N, Chapier R, Clouvel A, Colombier P, Conche M, Coquillard P, Corne C, CosteM, Dardelet M, Désir JP, Dieu de Freyssinette V, Dillies AF, Durando X, Dutheil C, FabreM, Fayolle J, Fleury J, Foirry JP, Fournier A, Fradin A, Fritz P, Gaouaoui H, Garcia M, Gayard A, Guérard A, Guérard E, Gerbaud L, Gérente Y, Germain JC, Grillou C, Guérin P, Guyot F, Héron AM, Isnard A, La Rivière C, Lefevre JP, Lelong S, Lémery S, Lyon-Belgy N, Mandard F, Marty L, Mathonnat J, Maurin L, Moreau I, Noirfalise C, Nore F, Paul E, Pavan C, Pelloux M, Phelipeau J, Porte M, Promeyrat JP, Raineau C, Raspilair J, Raynard F, Reynaud C, Roncet R, Salson V, Savy P, Sicot JL, Sobkowicz M, Tabone W, Tissier M, Vigier M, Vilmant R, Voorneveld V, Vuittenod M and Werner D. The trial was financed by AFRETH (French association for hydrothermal research). Auvergne Regional Council, Clermont-Communauté, League Against Cancer (Puy de Dôme committee CD63).

\section{CONFLICT OF INTEREST}

$\mathrm{RC}$ is involved in the AFRETH council. His role was to supervise the global study methodology/design and check for the trial quality. He did not interfere with the management of the trial, nor with statistical calculations and manuscript preparation.

\section{REFERENCES}

Aparicio-Ting FE, Farris M, Courneya KS, Schiller A, Friedenreich CM (2015) Predictors of physical activity at 12 month follow-up after a supervised exercise intervention in postmenopausal women. Int J Behav Nutr Phys Act 12: 55.

Courneya KS, Segal RJ, Mackey JR, Gelmon K, Reid RD, Friedenreich CM, Ladha AB, Proulx C, Vallance JK, Lane K, Yasui Y, McKenzie DC (2007) Effects of aerobic and resistance exercise in breast cancer patients receiving adjuvant chemotherapy: a multicenter randomised controlled trial. J Clin Oncol 25: 4396-4404.

Courneya KS, Sellar CM, Stevinson C, McNeely ML, Peddle CJ, Friedenreich CM, Tankel K, Basi S, Chua N, Mazurek A, Reiman T (2009) randomised controlled trial of the effects of aerobic exercise on physical functioning and quality of life in lymphoma patients. J Clin Oncol 27: 4605-4612.

Craft LL, VanIterson EH, Helenowski IB, Rademaker AW, Courneya KS (2012) Exercise effects on depressive symptoms in cancer survivors: a systematic review and meta-analysis. Cancer Epidemiol Biomarkers Prev 21: $3-19$.

Després JP (2012) Body fat distribution and risk of cardiovascular disease: an update. Circulation 126(10): 1301-1313.

Duijts SF, Faber MM, Oldenburg HS, van Beurden M, Aaronson NK (2011) Effectiveness of behavioral techniques and physical exercise on psychosocial functioning and health-related quality of life in breast cancer patients and survivors-a meta-analysis. Psychooncology 20(2): 115-126.

Greenlee H, Molmenti CL, Crew KD, Awad D, Kalinsky K, Brafman L, Fuentes D, Shi Z, Tsai WY, Neugut AI, Hershman DL (2016) Survivorship care plans and adherence to lifestyle recommendations among breast cancer survivors. J Cancer Surviv 10(6): 956-963.

Ibrahim EM, Al-Homaidh A (2011) Physical activity and survival after breast cancer diagnosis: meta-analysis of published studies. Med Oncol 28: $753-765$.

Kwiatkowski F, Girard M, Hacene K, Berlie J (2000) SEM: a suitable statistical software adapted for research in oncology. Bull Cancer 87(10): 715-721. 
Kwiatkowski F, Mouret-Reynier MA, Duclos M, Leger-Enreille A, Bridon F, Hahn T, Van Praagh-Doreau I, Travade A, Gironde M, Bézy O, Lecadet J, Vasson MP, Jouvency S, Cardinaud S, Roques CF, Bignon YJ (2013) Long term improved quality of life by a 2 -week group physical and educational intervention shortly after breast cancer chemotherapy completion. Results of the 'Programme of Accompanying women after breast Cancer treatment completion in Thermal resorts' (PACThe) randomised clinical trial of 251 patients. Eur J Cancer 49(7): 1530-1538.

Lépine JP, Godchau M, Brun P, Lempérière T (1985) Evaluation de l'anxiété et de la dépression chez des patients hospitalisés dans un service de médecine interne. Ann Med Psychol 143(2): 175-189.

Massie MJ (2004) Prevalence of depression in patients with cancer. J Natl Cancer Inst Monogr 32: 57-71.

Mourgues C, Gerbaud L, Leger S, Auclair C, Peyrol F, Blanquet M, Kwiatkowski F, Leger-Enreille A, Bignon YJ (2014) Positive and costeffectiveness effect of spa therapy on the resumption of occupational and non-occupational activities in women in breast cancer remission: a French multicentre randomised controlled trial. Eur J Oncol Nurs 18: 505-511.

Nichols HB, Trentham-Dietz A, Egan KM, Titus-Ernstoff L, Holmes MD, Bersch AJ, Holick CN, Hampton JM, Stampfer MJ, Willett WC, Newcomb PA (2009) Body mass index before and after breast cancer diagnosis: associations with all-cause, breast cancer, and cardiovascular disease mortality. Cancer Epidemiol Biomarkers Prev 18(5): 1403-1409.

Reich M, Lesur A, Perdrizet-Chevallier C (2008) Depression, quality of life and breast cancer: a review of the literature. Breast Cancer Res Treat 110: 9-17.

Richard JL, Bouzourene K, Gallant S, Ricciardi P, Richard JL, Sudre P, Iten A (2000) Validation et normes du SF-36 dans la population du canton de
Vaud. Lausanne: institut universitaire de médecine sociale et préventive. Raison Santé 28: 1-59.

Sun X, Nichols HB, Robinson W, Sherman ME, Olshan AF, Troester MA (2015) Post-diagnosis adiposity and survival among breast cancer patients: influence of breast cancer subtype. Cancer Causes Control 26(12): 1803-1811.

Trinh L, Mutrie N, Campbell AM, Crawford JJ, Courneya KS (2014) Effects of supervised exercise on motivational outcomes in breast cancer survivors at 5-year follow-up. Eur J Oncol Nurs 18(6): 557-563.

Walger O (2009) Empowerment et soutien social des personnes vivant avec un diabète: développement d'un outil d'évaluation a l'usage clinique. $E d u c$ Patient Enjeux Santé 27(1): 5-12.

Ware JE, Kosinski M, Keller SD (1994) SF-36 Physical And Mental Health Summary Scales: A User Manual. The Health Institute, New England Medical Centre: Boston, MA, USA.

Ware JE, Sherbourne CD (1992) 36-item short-form health survey (SF-36). I. Conceptual framework and item selection. Med Care 30: 473-483.

Zhu G, Zhang X, Wang Y, Xiong H, Zhao Y, Sun F (2016) Effects of exercise intervention in breast cancer survivors: a meta-analysis of 33 randomised controlled trails. Onco Targets Ther 9: 2153-2168.

Zigmond AS, Snaith RP (1983) The hospital anxiety and depression scale. Acta Psychiatr Scand 67: 361-370.

This work is published under the standard license to publish agreement. After 12 months the work will become freely available and the license terms will switch to a Creative Commons AttributionNonCommercial-Share Alike 4.0 Unported License. 